\title{
A Novel Positive Allosteric Modulator of the $\alpha 7$ Neuronal Nicotinic Acetylcholine Receptor: In Vitro and In Vivo Characterization
}

\author{
Raymond S. Hurst, ${ }^{1}$ Mihaly Hajós, ${ }^{1}$ Mario Raggenbass, ${ }^{2}$ Theron M. Wall, ${ }^{1}$ Nicole R. Higdon, ${ }^{1}$ Judy A. Lawson, ${ }^{1}$ \\ Karen L. Rutherford-Root, ${ }^{1}$ Mitchell B. Berkenpas, ${ }^{1}$ W. E. Hoffmann, ${ }^{1}$ David W. Piotrowski, ${ }^{1}$ Vincent E. Groppi, ${ }^{1}$ \\ Geraldine Allaman, ${ }^{2}$ Roch Ogier, ${ }^{2}$ Sonia Bertrand, ${ }^{2}$ Daniel Bertrand, ${ }^{2}$ and Stephen P. Arneric ${ }^{1}$ \\ ${ }^{1}$ Global Research and Development, Pfizer Inc., Groton, Connecticut 06340, and ${ }^{2}$ Department of Neuroscience, University of Geneva, CH-1211 Geneva 4 , \\ Switzerland
}

Several lines of evidence suggest a link between the $\alpha 7$ neuronal nicotinic acetylcholine receptor (nAChR) and brain disorders including schizophrenia, Alzheimer's disease, and traumatic brain injury. The present work describes a novel molecule, 1-(5-chloro-2,4dimethoxy-phenyl)-3-(5-methyl-isoxazol-3-yl)-urea (PNU-120596), which acts as a powerful positive allosteric modulator of the $\alpha 7$ nAChR. Discovered in a high-throughput screen, PNU-120596 increased agonist-evoked calcium flux mediated by an engineered variant of the human $\alpha 7 \mathrm{nAChR}$. Electrophysiology studies confirmed that PNU-120596 increased peak agonist-evoked currents mediated by wild-type receptors and also demonstrated a pronounced prolongation of the evoked response in the continued presence of agonist. In contrast, PNU-120596 produced no detectable change in currents mediated by $\alpha 4 \beta 2, \alpha 3 \beta 4$, and $\alpha 9 \alpha 10 \mathrm{nAChRs.} \mathrm{PNU-120596} \mathrm{increased}$ the channel mean open time of $\alpha 7 \mathrm{nAChRs}$ but had no effect on ion selectivity and relatively little, if any, effect on unitary conductance. When applied to acute hippocampal slices, PNU-120596 increased the frequency of ACh-evoked GABAergic postsynaptic currents measured in pyramidal neurons; this effect was suppressed by TTX, suggesting that PNU-120596 modulated the function of $\alpha 7 \mathrm{nAChRs}$ located on the somatodendritic membrane of hippocampal interneurons. Accordingly, PNU-120596 greatly enhanced the ACh-evoked inward currents in these interneurons. Systemic administration of PNU-120596 to rats improved the auditory gating deficit caused by amphetamine, a model proposed to reflect a circuit level disturbance associated with schizophrenia. Together, these results suggest that PNU-120596 represents a new class of molecule that enhances $\alpha 7 \mathrm{nAChR}$ function and thus has the potential to treat psychiatric and neurological disorders.

Key words: allosteric modulator; nicotinic receptor; $\alpha 7$; hippocampus; auditory gating; PNU-120596

\section{Introduction}

Among the neuronal nicotinic acetylcholine receptors (nAChRs), the $\alpha 7$ subtype is distinguished by its high permeability to $\mathrm{Ca}^{2+}$, its affinity for the antagonists $\alpha$-bungarotoxin and methyllycaconitine (MLA), and rapid desensitization (Couturier et al., 1990; Séguéla et al., 1993). Several studies have shown that $\alpha 7$ nAChRs can modulate the release of various neurotransmitters including glutamate, GABA, dopamine, and norepinephrine and thus have the potential to participate in a range of neurological functions (McGehee et al., 1995; Gray et al., 1996; Alkondon et al., 1997, 1999; Summers et al., 1997; Li et al., 1998; Schilstrom

Received Dec. 24, 2004; revised March 10, 2005; accepted March 28, 2005.

This work was supported in part by the Swiss National Science Foundation (D.B and M.R.). We are grateful to Dr. Rodney Walters for determining the brain concentration of PNU-120596 and to Dr. Janice Holland for providing the $\alpha 7$ nAChR-expressing GH4-C1 cell line.

Correspondence should be addressed to Raymond S. Hurst, Neurosciences Department, Global Research and Development, Pfizer Inc., Eastern Point Road 8220-4060, Groton, CT 06340. E-mail: raymond.s.hurst@pfizer.com.

T. M. Wall's and N. R. Higdon's present address: MPI Research, 54943 North Main Street, Mattawan, MI 49071-9399.

D0I:10.1523/JNEUROSC1.5269-04.2005

Copyright $\odot 2005$ Society for Neuroscience $\quad$ 0270-6474/05/254396-10\$15.00/0 et al., 1998; Maggi et al., 2001). For example, activation of $\alpha 7$ nAChRs can improve cognitive performance in rats (Arendash et al., 1995; Meyer et al., 1998; Levin et al., 1999; Van Kampen et al., 2004), rabbits (Woodruff-Pak et al., 1994; Woodruff-Pak, 2003), and monkeys (Briggs et al., 1997), whereas blockade of those receptors impairs performance (Felix and Levin, 1997; Bettany and Levin, 2001). Consistent with these animal studies, recent data from a small clinical study suggest that the $\alpha 7 \mathrm{nAChR}$ partial agonist GTS-21 (DMXB) positively influenced memory and attention in healthy volunteers (Kitagawa et al., 2003).

In view of these findings, pharmacological agents that selectively activate $\alpha 7 \mathrm{nAChRs}$ have been proposed as potential new strategies to treat several neurological and psychiatric disorders (for review, see Levin, 2002; Martin et al., 2004). In particular, schizophrenia has been associated with up to a $50 \%$ reduction of $\alpha 7 \mathrm{nAChR}$ protein in specific brain regions (Freedman et al., 1995; Court et al., 1999; Guan et al., 1999; Marutle et al., 2001), and it has been suggested that the high prevalence of smoking among schizophrenics may be a form of self-medication. More recently, an association between smoking and the $\alpha 7 \mathrm{nAChR}$ gene was found in schizophrenic patients (De Luca et al., 2004). 
In addition, a polymorphism in the $\alpha 7 \mathrm{nAChR}$ gene (CHRNA7) was found to be linked to the auditory gating deficit common in the schizophrenic patient population (Freedman et al., 1997). Consistent with its proposed involvement in sensory gating, selective agonists of $\alpha 7 \mathrm{nAChRs}$ have been shown to restore auditory gating deficits in rodent models of this impairment (Stevens et al., 1998; O’Neill et al., 2003; Hajós et al., 2005).

Although nicotinic agonists have shown some beneficial effects, chronic treatment of humans with such compounds has not been thoroughly characterized and may provide suboptimal benefit because of sustained activation and/or desensitization of the target receptor (Smith et al., 2002; Harris et al., 2004; White and Levin, 2004). A different approach would be to administer a nicotinic positive allosteric modulator (PAM) that can reinforce the endogenous cholinergic neurotransmission without directly stimulating the target receptors (for review, see Maelicke, 2000; Albuquerque et al., 2001). Several PAMs have been identified that increase the potency and/or maximal efficacy of agonists for the $\alpha 7$ nAChR; however, none of these agents has been shown to modify neuronal or circuit level activity in vivo (Krause et al., 1998; Zwart et al., 2002; Chimienti et al., 2003; Conroy et al., 2003; Zbarsky et al., 2004). Here, we report the discovery of a novel PAM of the $\alpha 7 \mathrm{nAChR,} \mathrm{1-(5-chloro-2,4-dimethoxy-}$ phenyl)-3-(5-methyl-isoxazol-3-yl)-urea (PNU-120596), which not only increases the potency and maximal efficacy of agonists but also dramatically prolongs the duration of the agonist-evoked macroscopic currents. Importantly, this work demonstrates that systemic administration of PNU-120596 improves auditory gating in rats impaired by amphetamine and thus provides the first demonstration of in vivo efficacy for an $\alpha 7 \mathrm{nAChR}$ PAM.

\section{Materials and Methods}

$\mathrm{Ca}^{2+}$ fluorescence assay. SH-EP1 human epithelial cells expressing a variant of the $\alpha 7 \mathrm{nAChR}\left(\alpha 7^{\star}\right)$ were grown in minimal essential medium (MEM) containing nonessential amino acids supplemented with $10 \%$ fetal bovine serum, L-glutamine, $100 \mathrm{U} / \mathrm{ml}$ penicillin/streptomycin, 250 $\mathrm{ng} / \mathrm{ml}$ fungizone, $400 \mu \mathrm{g} / \mathrm{ml}$ hygromycin $\mathrm{B}$, and $800 \mu \mathrm{g} / \mathrm{ml}$ geneticin. $\alpha 7^{\star}$ is a variant of the human $\alpha 7 \mathrm{nAChR}$, with two point mutations in the first transmembrane domain (T230P and C241S) that allow for high functional expression in SH-EP1 cells [Groppi VE, Wolfe ML, Berkenpas MB (2003) U.S. Patent 6,693,172 B1]. Cells were grown in a $37^{\circ} \mathrm{C}$ incubator with $6 \% \mathrm{CO}_{2}$. Cells were trypsinized and plated in 96 -well plates with dark side walls and clear bottoms at a density of $2 \times 10^{4}$ cells/well $2 \mathrm{~d}$ before analysis. Cells were loaded with a mixture of Calcium Green-1 AM (Molecular Probes, Eugene, OR) in anhydrous dimethylsulfoxide and $20 \%$ pluronic F-127 (Molecular Probes). This reagent was added directly to the growth medium of each well to achieve a final concentration of 2 $\mu \mathrm{M}$ Calcium Green-1 AM. Cells were then incubated in the dye for $1 \mathrm{~h}$ at $37^{\circ} \mathrm{C}$ and then washed four times with Mark's modified Earle's balanced salt solution (MMEBSS) composed of the following (in $\mathrm{mM}$ ): $4 \mathrm{CaCl}_{2}, 0.8$ $\mathrm{MgSO}_{4}, 20 \mathrm{NaCl}, 5.3 \mathrm{KCl}, 5.6 \mathrm{D}$-glucose, 20 Tris-HEPES, and 120 $N$-methyl-D-glucamine, $\mathrm{pH}$ 7.4. After the fourth cycle, the cells were allowed to incubate at $37^{\circ} \mathrm{C}$ for at least $10 \mathrm{~min}$. The final volume of MMEBSS in each well was $100 \mu \mathrm{l}$ and atropine was added to all wells for a final concentration of $1 \mu \mathrm{M}$.

A fluorometric imaging plate reader (FLIPR; Molecular Devices, Union City, CA) was set up to excite Calcium Green at $488 \mathrm{~nm}$ using 500 $\mathrm{mW}$ of power and reading fluorescence emission of $>525 \mathrm{~nm}$. A $0.5 \mathrm{~s}$ exposure was used to illuminate each well. Fluorescence was detected using an F-stop set of either 2.0 or 1.2. After $30 \mathrm{~s}$ of baseline recording, test compounds were added to each well of a 96 -well plate in $50 \mu \mathrm{l}$ of a $3 \times$ stock. In each experiment, four wells were used as vehicle (0.2\% DMSO) controls.

Oocyte preparation and recording. Xenopus oocytes were prepared as described previously (Bertrand et al., 1991). Briefly, ovaries were dissected from a Xenopus laevis female after anesthesia, and oocytes were isolated by mechanical and enzymatic treatments. On the following day, stage 5-6 oocytes were selected under the microscope, and $2 \mathrm{ng}$ of expression vectors containing the desired cDNAs were injected into the oocyte nucleus. Oocytes were then placed in individual wells of a 96-well plate and incubated for $2-3 \mathrm{~d}$ at $18^{\circ} \mathrm{C}$ in BARTH solution that contained (in mM) $88 \mathrm{NaCl}, 1 \mathrm{KCl}, 2.4 \mathrm{NaHCO}_{3}, 10$ HEPES, $0.82 \mathrm{MgSO}_{4}, 0.33$ $\mathrm{Ca}\left(\mathrm{NO}_{3}\right)_{2}$, and $0.41 \mathrm{CaCl}_{2}, \mathrm{pH} 7.4$, supplemented with $20 \mu \mathrm{g} / \mathrm{ml}$ kanamycin, $100 \mathrm{U} / \mathrm{ml}$ penicillin, and $100 \mu \mathrm{g} / \mathrm{ml}$ streptomycin.

Properties of oocytes were investigated using two-electrode voltage clamp (GeneClamp; Molecular Devices). During the recordings, oocytes were superfused at $6 \mathrm{ml} / \mathrm{min}$ with oocyte Ringer's solution (OR2) that contained the following (in mM): $82.5 \mathrm{NaCl}, 2.5 \mathrm{KCl}, 5 \mathrm{HEPES}, 2.5 \mathrm{CaCl}_{2}$, and $1 \mathrm{MgCl}_{2}, \mathrm{pH} 7.4$, and $0.5 \mu \mathrm{M}$ atropine was added to block endogenous muscarinic receptors. Bovine serum albumin $(20 \mathrm{mg} / \mathrm{ml})$ was added to the perfusion media to prevent adsorption of the compounds to the plastic. All compounds were diluted in OR2 medium just before the experiment; delivery of perfusion medium was made through electrovalves. To prevent contamination of the ACh-evoked responses by the contribution of endogenous $\mathrm{Ca}^{2+}$-activated chloride currents, oocytes were treated with $100 \mu \mathrm{M}$ BAPTA-AM for at least $3 \mathrm{~h}$.

Concentration-response curves were fit using the empirical Hill equation:

$$
y=1+\left(\mathrm{EC}_{50} / x\right)^{n_{H}},
$$

where $y$ is the fraction of remaining current, $\mathrm{EC}_{50}$ is the concentration of half-maximal efficacy, $n_{H}$ is the Hill coefficient, and $x$ is agonist concentration. Values indicated throughout the text are given with their respective SEM. Current-voltage $(I-V)$ relationships were fit according to the following equation:

$$
y=\left(G+G_{\text {cte }}\right) \times\left(V-V_{\mathrm{e}}\right) /\left(1+\exp -\alpha\left(V-V_{\mathrm{o}}\right)\right),
$$

where $y$ is the membrane current, $G$ is the maximal voltage-dependent conductance, $G_{\text {cte }}$ is the voltage-independent conductance, $\alpha$ is the slope of the Boltzman equation, $V_{\mathrm{o}}$ is the voltage for half-activation, $V_{\mathrm{e}}$ is the reversal potential, and $V$ is the transmembrane potential. Statistical comparisons were performed with a two-tailed Student's $t$ test.

Neuron isolation and culture conditions. Sprague Dawley rats [postnatal day 3 (P3)] were decapitated, and the brains were removed and placed in ice-cold Hibernate A medium. Hippocampal regions were gently removed, cut into small pieces, and placed in Hibernate-A medium with 1 $\mathrm{mg} / \mathrm{ml}$ papain for $60 \mathrm{~min}$ at $35^{\circ} \mathrm{C}$. After digestion, the tissues were washed several times in Hibernate A media and transferred to a $50 \mathrm{ml}$ conical tube containing $6 \mathrm{ml}$ of Hibernate A medium with B27 supplement (2\%). Neurons were dissociated by gentle trituration through a series of three 9-inch Pasteur pipettes with decreasing tip diameters. Cells were purified over a Nycoprep gradient according to the methods of Brewer (1997). Cells were plated onto poly-D-lysine/laminin-coated coverslips at a density of $300-700$ cells $/ \mathrm{mm}^{2}$, allowed to adhere for $1 \mathrm{~h}$ at room temperature, and then transferred to 24-well tissue-culture plates containing warmed culture medium composed of Neurobasal-A medium, B27 supplement $(2 \%)$, L-glutamine $(0.5 \mathrm{~mm}), 100 \mathrm{U} / \mathrm{ml}$ penicillin, $100 \mathrm{mg} / \mathrm{ml}$ streptomycin, and $0.25 \mathrm{mg} / \mathrm{ml}$ fungizone. Cells were maintained in a humidified incubator at $37^{\circ} \mathrm{C}$ and $6 \% \mathrm{CO}_{2}$ for $1-2$ weeks. The medium was changed after $24 \mathrm{~h}$ and then approximately every $3 \mathrm{~d}$ thereafter. Cell culture reagents were purchased from Invitrogen (Carlsbad, CA).

Brain slice preparation. Sprague Dawley rats ranging from P16 to P21 were anesthetized with halothane or pentobarbital $(50 \mathrm{mg} / \mathrm{kg}$, i.p.) and decapitated. The brain was removed, and a block containing the hippocampus was prepared. Coronal slices (350 $\mu \mathrm{m}$ thick) were cut using either a Microslicer (DSK 1500E; Dosaka, Tokyo, Japan) or a vibrating microtome (Campden Instruments, Loughborough, UK) in ice-cold slicing buffer composed of the following (in $\mathrm{mm}$ ): $130 \mathrm{NaCl}, 26 \mathrm{NaHCO}_{3}$, $1.25 \mathrm{NaH}_{2} \mathrm{PO}_{4}, 3 \mathrm{KCl}, 0.5 \mathrm{CaCl}_{2}, 10 \mathrm{MgCl}_{2}, 10$ glucose, 0.4 ascorbic acid, and 0.2 lidocaine, continuously bubbled with a mixture of $95 \% \mathrm{O}_{2} / 5 \%$ $\mathrm{CO}_{2}$.

Patch-clamp electrophysiology. Membrane currents were recorded using an Axopatch 200B amplifier (Molecular Devices). Analog signals were filtered at one-fifth the sampling frequency, digitized, stored, and 
measured using pClamp software (Molecular Devices). Patch pipettes were pulled from borosilicate capillary glass using a Flaming/Brown micropipette puller (P97; Sutter Instrument, Novato, CA). Cultured neurons were continuously superfused with an external bath solution containing the following (in $\mathrm{mM}$ ): $140 \mathrm{NaCl}, 5 \mathrm{KCl}, 2 \mathrm{CaCl}_{2}, 1 \mathrm{MgCl}_{2}, 10$ HEPES, and 10 glucose, $\mathrm{pH}$ 7.4. Bicuculline $(10 \mu \mathrm{M}), \mathrm{CNQX}(5 \mu \mathrm{M})$, and tetrodotoxin $(0.5 \mu \mathrm{M})$ were included in the bath solution to inhibit synaptic activity. Patch pipettes were filled with an internal solution composed of the following (in mM): $126 \mathrm{CsCH}_{3} \mathrm{SO}_{3}, 10 \mathrm{CsCl}, 4 \mathrm{NaCl}, 1$ $\mathrm{MgCl}_{2}, 0.5 \mathrm{CaCl}_{2}, 5$ EGTA, 10 HEPES, 3 ATP-Mg, 0.3 GTP-Na, and 4 phosphocreatin, $\mathrm{pH}$ 7.2. Solutions containing test compounds were delivered via a multibarrel fast perfusion exchange system (Warner Instruments, Hamden, CT).

Recordings from acutely isolated brain slices were performed using a Zeiss (Oberkochen, Germany) Axioskop or a Nikon (Tokyo, Japan) Eclipse E600FN equipped with infrared (IR)-differential interference contrast optics and water-immersion objectives. Neurons were visualized using an IR video camera [type C 25400-07 (Hamamatsu, Schüpfen, Switzerland) or type C2400-77E (Hamamatsu, Shizuoka, Japan)]. The preparation was continuously superfused $(2-4 \mathrm{ml} / \mathrm{min})$ with a recording buffer composed of the following (in $\mathrm{mm}$ ): $130 \mathrm{NaCl}, 26 \mathrm{NaHCO}_{3}, 1.25$ $\mathrm{NaH}_{2} \mathrm{PO}_{4}, 3 \mathrm{KCl}, 2 \mathrm{CaCl}_{2}, 1 \mathrm{MgCl}_{2}, 10$ glucose, and 0.4 ascorbic acid, saturated with a mixture of $95 \% \mathrm{O}_{2} / 5 \% \mathrm{CO}_{2}$. D-AP-5 (10-20 $\left.\mu \mathrm{M}\right)$, CNQX or 6,7-dinitroquinoxaline-2,3-dione (5 $\mu \mathrm{M})$, and atropine (1-5 $\mu \mathrm{M})$ were present in the perfusion solution throughout most experiments. ACh was either added to the perfusion solution or pressureejected from a patch-type pipette $(100-500 \mathrm{~ms}$; one to two bars) positioned near the neuron tested. To record IPSCs, patch pipettes were filled with a high chloride solution composed of the following (in $\mathrm{mM}$ ): 136 $\mathrm{CsCl}, 4 \mathrm{NaCl}, 1 \mathrm{MgCl}_{2}, 0.5 \mathrm{CaCl}_{2}, 5$ EGTA, 10 HEPES, 3 ATP-Mg, 0.3 GTP-Na, and 4 phosphocreatin, $\mathrm{pH}$ 7.2. Some recordings were made using patch pipettes filled with the following solution (in $\mathrm{mM}$ ): $150 \mathrm{CsCl}$, 10 HEPES, $4 \mathrm{MgCl}_{2}, 0.1$ BAPTA, $2 \mathrm{Na}_{2}$-ATP, and 0.4 $\mathrm{Na}_{2}$-GTP, pH 7.2. $\mathrm{N}$-(2,6-dimethylphenylcarbamoylmethyl) triethylammonium bromide ( 1 or $4 \mathrm{~mm}$ ) was included in the pipette solution for experiments measuring synaptic activity in brain slices. The resistance of the patch pipettes when filled with internal solution ranged from 3 to $6 \mathrm{M} \Omega$. For experiments measuring ACh-evoked inward current in interneurons of acutely isolated hippocampal slices, patch pipettes were filled with the same solution as above, except that $\mathrm{CsCl}$ was replaced with $140 \mathrm{~mm}$ $\mathrm{K}$-gluconate and $10 \mathrm{~mm} \mathrm{KCl}$. All data are reported as mean \pm SEM.

Auditory gating experiments in anesthetized rats. Experiments were performed as described previously (Krause et al., 2003; Hajós et al., 2005). In brief, male Sprague Dawley rats (weighing 250-300 g) were anesthetized with chloral hydrate $(400 \mathrm{mg} / \mathrm{kg}$, i.p.). The femoral artery and vein were cannulated for monitoring of arterial blood pressure and administration of additional anesthetic and test agents, respectively. The anesthetized rat was placed in a Kopf stereotaxic frame (David Kopf Instruments, Tujunga, CA), and unilateral craniotomy was performed above the hippocampus. Body temperature of the rat was maintained at $37^{\circ} \mathrm{C}$. Field potentials (electroencephalogram) were recorded from the CA3 region of the left hippocampus, $3.8 \mathrm{~mm}$ ventral, $3.5 \mathrm{~mm}$ posterior, and $3.0 \mathrm{~mm}$ lateral from bregma (Paxinos and Watson, 1986), using a monopolar stainless-steel macroelectrode (Rhodes Medical Instruments, Woodland Hills, CA). Data were digitized and stored using the Spike2 software package (Cambridge Electronic Design, Cambridge, UK). Auditory stimulation consisted of two consecutive tone bursts, $10 \mathrm{~ms}$ in duration, at a frequency of $5 \mathrm{kHz}$, delivered through hollow ear bars. Delay between the first "conditioning stimulus" and second "test stimulus" was $0.5 \mathrm{~s}$, and the time interval between tone pairs was $10 \mathrm{~s}$. Auditory evoked potentials (EPs) were determined by measuring the potential difference between the positive and the negative deflections 20 and $40 \mathrm{~ms}$ after stimulation (P20 and N40), respectively. For quantification, 50 sweeps were averaged, amplitudes of EPs were determined, and the level of sensory gating was expressed as percentage of gating: ( 1 - test amplitude/ conditioning amplitude $) \times 100$. Amphetamine $(\mathrm{D}$-amphetamine sulfate, $1 \mathrm{mg} / \mathrm{kg}$, i.v.) was administered to disrupt sensory gating. PNU-120596 or its vehicle (5\% DMSO and 5\% Solutol in PBS) was applied subsequently, and auditory gating measurements started $5 \mathrm{~min}$ after com-
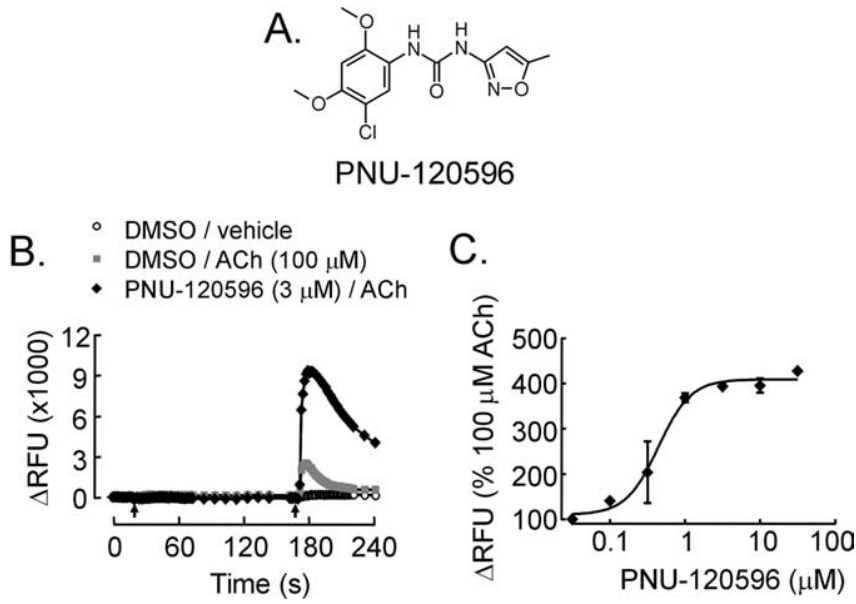

Figure 1. PNU-120596 enhances $\mathrm{Ca}^{2+}$ flux mediated by an engineered variant of the human $\alpha 7$ nAChR. $\boldsymbol{A}$, Chemical structure of PNU-120596. $\boldsymbol{B}$, Plot of the change in relative fluorescence units ( $\triangle \mathrm{RFU}$ ) mediated by $\alpha 7^{*}$ expressed in SH-EP1 cells. Cells were pretreated with either vehicle (0.2\% DMSO) or $3 \mu \mathrm{M}$ PNU-120596 (first arrow) and subsequently challenged with either buffer or $100 \mu \mathrm{m} \mathrm{ACh}$ (second arrow). Open circles indicate cells treated first with DMSO and then challenged with buffer, gray squares indicate cells treated first with DMSO and then challenged with ACh, and black diamonds indicate cells treated first with PNU-120596 and then challenged with ACh. C, Concentration-response relationship of PNU-120596 determined from $\alpha 7^{*}$-expressing SH-EP1 cells $\left(\mathrm{EC}_{50}=216 \pm 64 \mathrm{~nm} ; n=51\right)$. Error bars represent SEM.

pound or vehicle administration; efficacy was calculated as percentage of reversal of amphetamine-induced gating deficit (percentage reversal). Statistical significance was determined by means of a two-tailed paired Student's $t$ test.

All procedures involving animals were conducted under an approved animal use protocol in compliance with the Animal Welfare Act Regulations (Code of Federal Regulations, Title 9, parts 1-3) and with the Guide for the Care and Use of Laboratory Animals, National Institutes of Health guidelines, or the Swiss Federal Veterinary Office.

\section{Results}

PNU-120596 selectively enhances the function of $\alpha 7 \mathrm{nAChRs}$

PNU-120596, shown in Figure $1 A$, was discovered in a cell-based $\mathrm{Ca}^{2+}$ flux assay using an engineered variant of the human $\alpha 7$ nAChR stably expressed in SH-EP1 cells (see Materials and Methods). As illustrated in Figure $1 \mathrm{~B}$, ACh $(100 \mu \mathrm{M})$ added alone to $\alpha 7^{\star}$-expressing SH-EP1 cells evoked a small transient increase in $\mathrm{Ca}^{2+}$ plotted as the change in relative fluorescence units compared with baseline. Pretreatment of the same cells with PNU$120596(3 \mu \mathrm{M})$ produced no change in fluorescence when added alone but markedly increased the $\mathrm{Ca}^{2+}$-mediated signal in response to a subsequent challenge with $\mathrm{ACh}$. Atropine was present at a concentration of $1 \mu \mathrm{M}$ throughout the experiment to block endogenous muscarinic receptors. Concentration-response measurements of PNU-120596 for enhancing ACh-evoked $\mathrm{Ca}^{2+}$ flux in $\alpha 7^{\star}$-expressing SH-EP1 cells yielded an $\mathrm{EC}_{50}$ of $216 \pm 64$ $\mathrm{nM}(n=51)$ (Fig. $1 C)$.

To further characterize the effects and mechanisms of action of PNU-120596, we examined its action on agonist-evoked currents in Xenopus oocytes expressing the wild-type human $\alpha 7$ nAChR. When PNU-120596 was preapplied for $20 \mathrm{~s}$, a marked increase in the response to the agonists choline and ACh was observed together with an important prolongation of the current duration (Fig. 2A). Incubation with PNU-120596 resulted in a large increase in the agonist-evoked currents, even at concentrations of agonist that evoked maximal responses in control conditions (Fig. $2 B$ ). Figure $2 C$ shows the concentration-response relationships for ACh measured in control conditions and during 


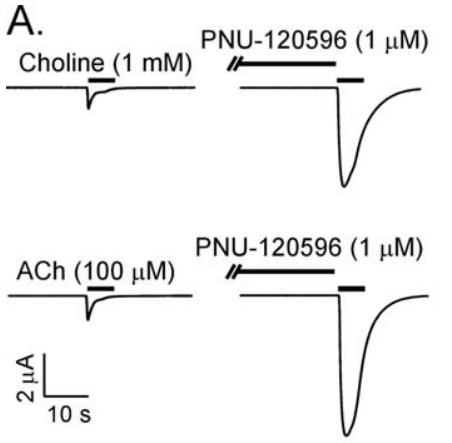

C.

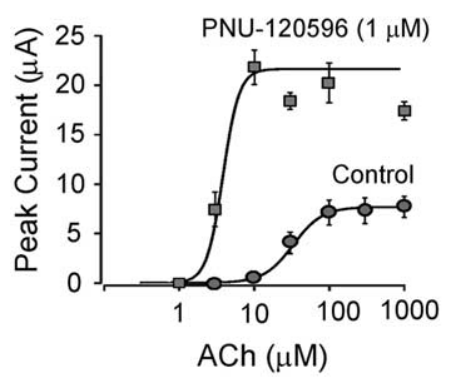

B.

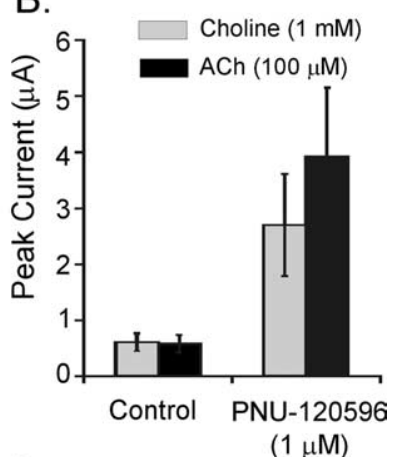

D.

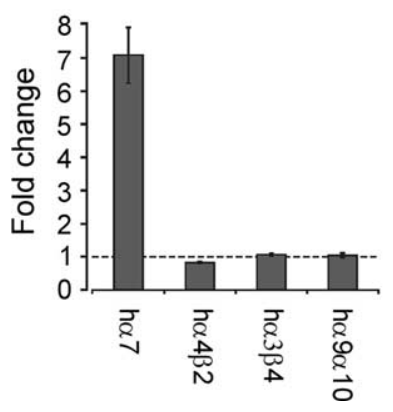

Figure 2. PNU-120596 selectively enhances the function of human $\alpha 7 \mathrm{nAChRs.} \boldsymbol{A}$, Typical currents recorded in response to a brief test pulse $(3 \mathrm{~s})$ of either choline (1 mm) or ACh (100 $\mu \mathrm{m})$ in an oocyte expressing the human $\alpha 7 \mathrm{nAChR}$. Time course of typical responses recorded before and after $20 \mathrm{~s}$ of pretreatment with $1 \mu \mathrm{M}$ PNU-120596. $\boldsymbol{B}$, Plot of the mean current amplitude evoked by choline and ACh in the absence and presence of PNU-120596 (1 $\mu \mathrm{m})$. C, Plot of the average peak current as a function of ACh concentration $(n=4)$. Currents evoked by a series of ACh pulses were recorded first in control and then after PNU-120596 exposure (same protocol as in $\boldsymbol{A}$ ). Data points are the average of three cells, and error bars indicate the SDs. Curves through the data points are the best fit obtained with the empirical Hill equation. The $\mathrm{EC}_{50}$ and $n_{H}$ values were $33.7 \pm 5.3$ and $2.2 \pm 0.4 \mu \mathrm{m}(n=4)$ for control conditions and $3.8 \pm 0.5$ and $4 \pm 0.4$ $\mu \mathrm{m}(n=5)$ in the presence of PNU-120596. D, The effects of PNU-120596 are specific to the $\alpha 7$ subtype of nAChR. Ratios of peak current amplitude expressed as fold change recorded before and after PNU-120596 (1 $\mu \mathrm{m})$ incubation were measured in another batch of 00cytes expressing different human nAChR subtypes. ACh test pulses were $100 \mu \mathrm{m}$ for $\alpha 7$ ( $n=4), 50 \mu \mathrm{m}$ for $\alpha 4 \beta 2(n=4), 50 \mu \mathrm{m}$ for $\alpha 3 \beta 4(n=4)$, and $10 \mu \mathrm{m}$ for $\alpha 9 \alpha 10(n=4)$. Error bars represent SEM.

continuous exposure to PNU-120596. These data revealed that PNU-120596 increased the maximal response and potency of the agonist and increased the apparent cooperativity (Hill coefficient). To assess the specificity of PNU-120596 for the $\alpha 7$ $\mathrm{nAChR}$, effects of this compound were tested at other neuronal nicotinic acetylcholine receptors expressed in oocytes. As shown in Figure 2D, PNU-120596 exposure caused a potentiation only at $\alpha 7$ nAChRs.

Although oocytes provide a clear demonstration of the selectivity of PNU-120596 and suggest that this compound slows down the ACh-evoked current, this preparation does not allow conclusions to be made about the kinetic properties of native receptors. To overcome this limitation, we therefore examined the effects of PNU-120596 on native receptors in neurons. Consistent with the results using the expressed human receptor, $1 \mu \mathrm{M}$ PNU-120596 markedly enhanced the ACh-evoked currents recorded from cultured rat hippocampal neurons (Fig. 3Aa). Figure $3 A b$ shows the same data as Figure $3 A a$, but the current amplitudes are normalized to highlight the effects of PNU-120596 on the decay of the currents in the continued presence of agonist. In the absence of PNU-120596, the currents decayed to baseline

Aa

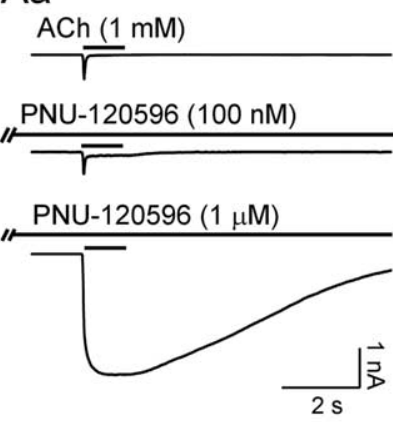

B

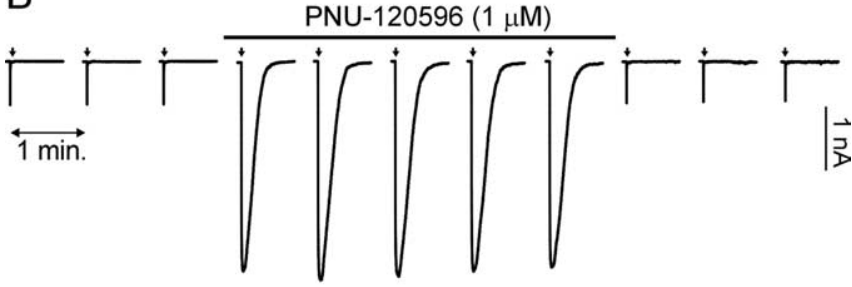

C
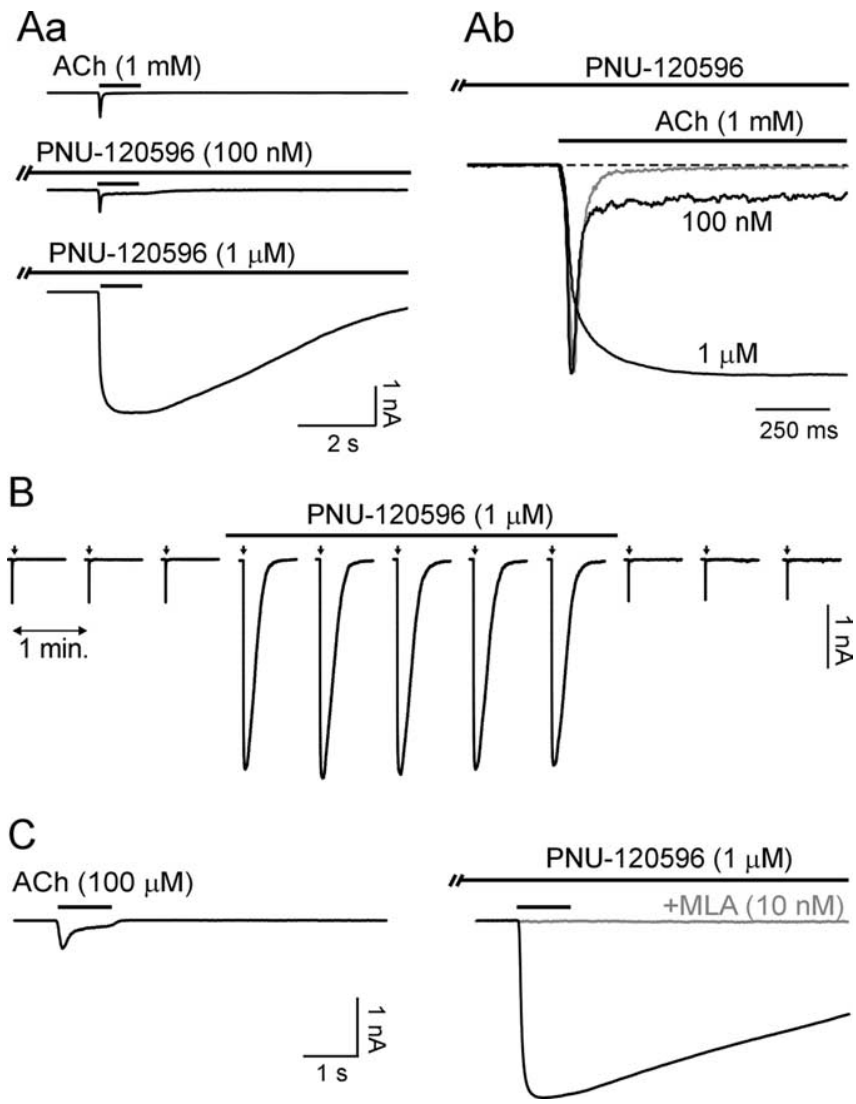

\section{宣}

Figure 3. PNU-120596 potentiates endogenous $\alpha 7 \mathrm{nAChRs}$ of cultured rat hippocampal neurons. Aa, Example of currents evoked by $1 \mathrm{~mm} \mathrm{ACh}$ alone (top trace) and in the presence of $0.1 \mu \mathrm{M}$ PNU-120596 (middle trace) or $1 \mu \mathrm{M}$ PNU-120596 (bottom trace); PNU-120596 was added $\sim 30$ s before ACh in each case. $\boldsymbol{A} \boldsymbol{b}$, The same data as in $\boldsymbol{A} \boldsymbol{a}$ but on an expanded time scale; the current amplitudes have been normalized. The gray trace shows the currents evoked by $1 \mathrm{~mm} A C h$ in the absence of PNU-120596. B. Consecutive responses to $1 \mathrm{~s}$ challenges with ACh (arrows; $1 \mathrm{~mm}$ ) repeated once per minute. PNU-120596 was applied continuously for $\sim 5$ min as indicated by the horizontal bar. C, Currents evoked by $100 \mu \mathrm{M}$ ACh alone (left) and in the presence of $1 \mu \mathrm{M}$ PNU-120596 (right). Currents recorded in the presence of PNU-120596 were recorded in the absence (black trace) and presence (gray trace) of $10 \mathrm{~nm} M L A$.

within a few hundred milliseconds during exposure to $1 \mathrm{~mm}$ ACh. Pretreatment and cotreatment with $100 \mathrm{nM}$ PNU-120596 produced little or no change in the peak ACh-evoked current but significantly slowed the current decay. Treatment with $1 \mu \mathrm{M}$ PNU-120596 virtually eliminated the decay of current during the $1 \mathrm{~s}$ challenge with ACh. This property of PNU-120596 is in contrast to that of other PAMs described previously for the $\alpha 7$ nAChR, which appear to have relatively little or no effect on the decay of the macroscopic currents (Krause et al., 1998; Zwart et al., 2002; Chimienti et al., 2003; Conroy et al., 2003; Zbarsky et al., 2004). As illustrated in Figure 3B, the effects of PNU-120596 were maintained during a prolonged exposure. In this example, PNU120596 was applied continuously for $\sim 5 \mathrm{~min}$ while ACh ( $1 \mathrm{~mm}$ ) was applied repeatedly at $1 \mathrm{~min}$ intervals; each application was $1 \mathrm{~s}$ in duration. On average, the amplitude of the first ACh-evoked response measured in the presence of PNU-120596 was $625 \pm$ $165 \%(n=4)$ of the control ACh response and was indistinguishable from the responses recorded after $\sim 5 \mathrm{~min}$ of continuous exposure to PNU-120596 (678 $\pm 213 \% ; n=4)$. The effects of PNU-120596 rapidly reversed during washout, and the AChevoked currents returned to baseline levels. To test whether PNU-120596 acted on $\alpha 7$-containing nAChRs in the cultured neurons, ACh was applied to cells pretreated and cotreated with 


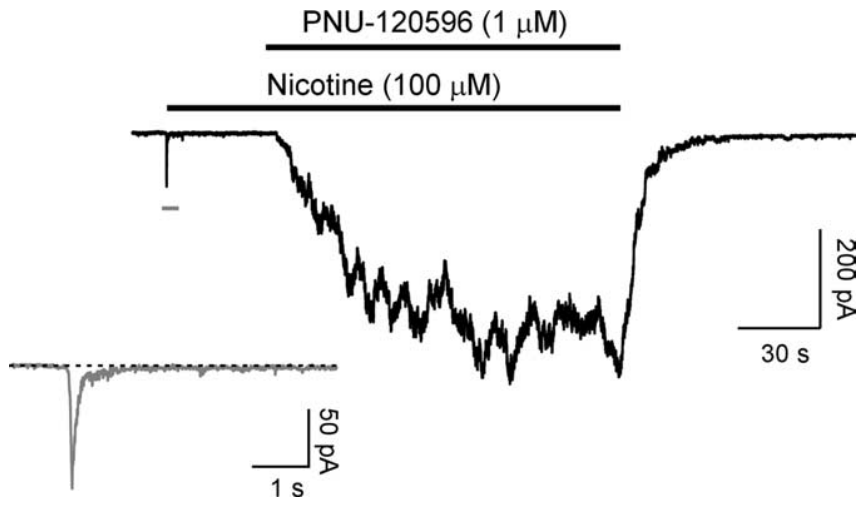

Figure 4. PNU-120596 can activate desensitized $\alpha 7 \mathrm{nAChRs}$. Nicotine (100 $\mu \mathrm{m})$ was applied to cultured rat hippocampal neurons for a duration of $2.5 \mathrm{~min}$. After $30 \mathrm{~s}$ of continuous exposure to nicotine, PNU-120596 $(1 \mu \mathrm{m})$ was coapplied for an additional $2 \mathrm{~min}$. The duration of exposure to nicotine and PNU-120596 is indicated by the black horizontal bars above the top trace. The initial response to nicotine is shown by the bottom trace (gray); the small gray bar indicates the region from the top trace that is expanded in the bottom trace.

both PNU-120596 (1 $\mu \mathrm{M})$ and the selective $\alpha 7 \mathrm{nAChR}$ antagonist MLA (10 nM). As illustrated in Figure 3C, PNU-120596 failed to potentiate the ACh-evoked response when measured in the presence of MLA $(n=3)$. The cell used for this example was typical of most cultured hippocampal neurons and predominantly expressed MLA-sensitive ACh-evoked currents (Alkondon and Albuquerque, 1993; Zarei et al., 1999). Thus, these data, in combination with the results shown in Figure $2 D$, provide good evidence that PNU-120596 enhanced the function only of nAChRs containing the $\alpha 7$ subunit.

A substantial difference between PNU-120596 and previously described PAMs of the $\alpha 7 \mathrm{nAChR}$ is that PNU-120596 greatly prolongs the whole-cell response evoked by agonist. We further explored this property by testing whether PNU-120596 could convert $\alpha 7 \mathrm{nAChRs}$ that were already desensitized by a high concentration of an agonist back to a conducting state. For this experiment, cultured rat hippocampal neurons were exposed to a relatively high concentration of nicotine $(100 \mu \mathrm{M})$ for $30 \mathrm{~s}$ to activate and fully desensitize the $\alpha 7 \mathrm{nAChRs}$. Subsequently, in the continued presence of nicotine, PNU-120596 (1 $\mu \mathrm{M})$ was coapplied for an additional 2 min. As illustrated in Figure 4, the subsequent addition of PNU-120596 resulted in a large and sustained inward current that was readily reversed during washout. The current evoked by PNU-120596 developed slowly and was, on average, $475 \pm 85 \%(n=4)$ of the peak current evoked by the initial application of nicotine. These results suggest that PNU120596 activated receptors that were presumably agonist-bound but desensitized.

The effects caused by PNU-120596 can be attributed to different mechanisms that include reduction of desensitization, allosteric potentiation, modification of the channel properties, etc. To examine whether PNU-120596 modifies the channel properties of the $\alpha 7 \mathrm{nAChR}$, we first tested whether PNU-120596 altered the reversal potential of the ACh-evoked currents and then determined how single-channel properties were affected. Voltage ramps from -100 to $40 \mathrm{mV}$ were applied during the peak response evoked by $10 \mu \mathrm{M}$ ACh with and without $1 \mu \mathrm{M}$ PNU120596 in the bath solution (Fig. 5A). As expected for an allosteric modulator, PNU-120596 caused an important increase in the current amplitude but no detectable change in either the reversal potential or the voltage dependency. The solid lines in Figure $5 B$ are the best fit obtained with Equation 2; both curves have iden-
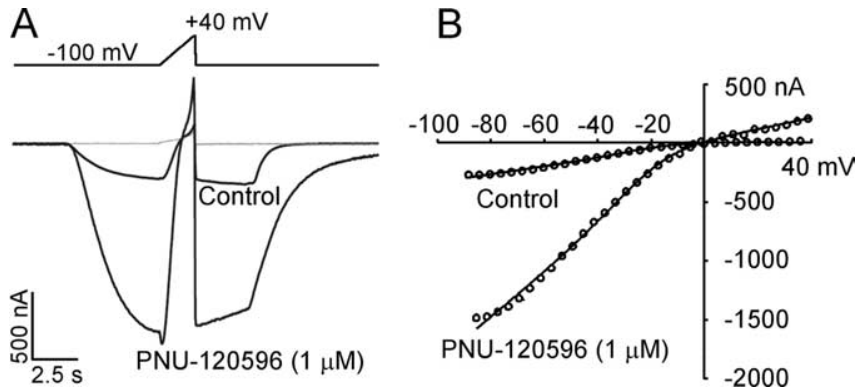

Figure 5. PNU-120596 does not modify the ion selectivity of $\alpha 7 \mathrm{nAChRs}$. A, Currents evoked by low $\mathrm{ACh}$ concentration $(10 \mu \mathrm{m})$ were recorded first in control conditions and after exposure to PNU-120596. Application of a voltage ramp during the ACh application allowed the determination of the current-voltage relationship shown in $\boldsymbol{B}$. Lines through the data points are the best fits obtained using $0 \mathrm{hm}$ 's Law and a Boltzman equation to mimic the voltage dependency (see Materials and Methods). Parameters for the equation were not statistically different $\left(V_{\mathrm{e}}=\right.$ $0 \mathrm{mV} ; \alpha=0.88 ; V_{0}=-21.8 \mathrm{mV}$ ) in the two conditions, except for the conductances $G=2.3$ $\mathrm{nS}, G_{\mathrm{cte}}=0.4 \mathrm{nS}$ in control and $\mathrm{G}=13.3 \mathrm{nS}, G_{\mathrm{cte}}=4.5 \mathrm{nS}$ after PNU-120596 exposure. Values are the mean results obtained from six oocytes.
$\mathrm{Aa}$

Nicotine $(100 \mu \mathrm{M})$

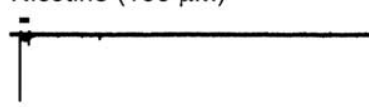

$\mathrm{Ba}$

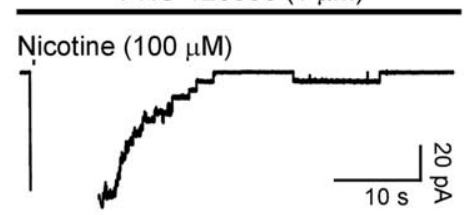

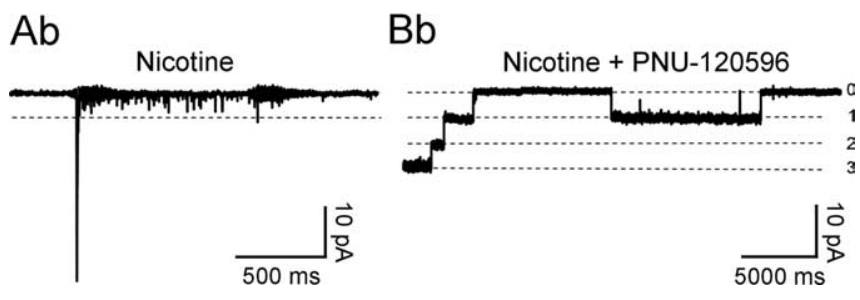

Figure 6. PNU-120596 increases the open time of $\alpha 7 \mathrm{nAChRs.Aa,Ba}$, Examples of nicotineevoked currents recorded from the same outside-out membrane patch in the absence $(\boldsymbol{A} \boldsymbol{a})$ and presence $(\boldsymbol{B a})$ of $1 \mu \mathrm{M}$ PNU-120596. Membrane patches were pulled from $\mathrm{GH} 4-\mathrm{C} 1$ cells expressing the rat $\alpha 7 \mathrm{nAChR}$. In this example, nicotine was applied for $1 \mathrm{~s}$ when given alone and for 250 $\mathrm{ms}$ in the presence of PNU-120596; a shorter application of nicotine was required in the presence of PNU-120596 to capture the complete decay of current. $\boldsymbol{A} \boldsymbol{b}, \boldsymbol{B} \boldsymbol{b}$, Expanded regions of the same data as above. Note the 10 -fold difference in the time scale between $\boldsymbol{A} \boldsymbol{b}$ and $\boldsymbol{B} \boldsymbol{b}$.

tical parameters except for the conductance. This illustrates that the effects PNU-120596 do not involve an alteration of the ion selectivity of $\alpha 7$ nAChRs.

The effects of PNU-120596 on single-channel properties were evaluated with outside-out patch recordings from GH4-C1 cells expressing the rat $\alpha 7 \mathrm{nAChR}$. Nicotine-evoked currents were recorded from membrane patches before and during continuous exposure to PNU-120596 (1 $\mu \mathrm{M})$. When applied alone, nicotine evoked a brief initial spike in channel activity reflecting the simultaneous opening of several channels, followed by brief unitary events occurring for the duration of the $1 \mathrm{~s}$ application of agonist (Fig. 6A). Figure $6 B$ shows a nicotine-evoked current $(250 \mathrm{~ms}$ application) from the same membrane patch as Figure $6 \mathrm{~A}$ but in the presence of $1 \mu \mathrm{M}$ PNU-120596. As expected, the peak response was greatly increased, and the response was markedly prolonged. Even after the removal of nicotine, the currents slowly returned to baseline levels in the continued presence of PNU120596. Careful examination of the currents as they returned to 
A
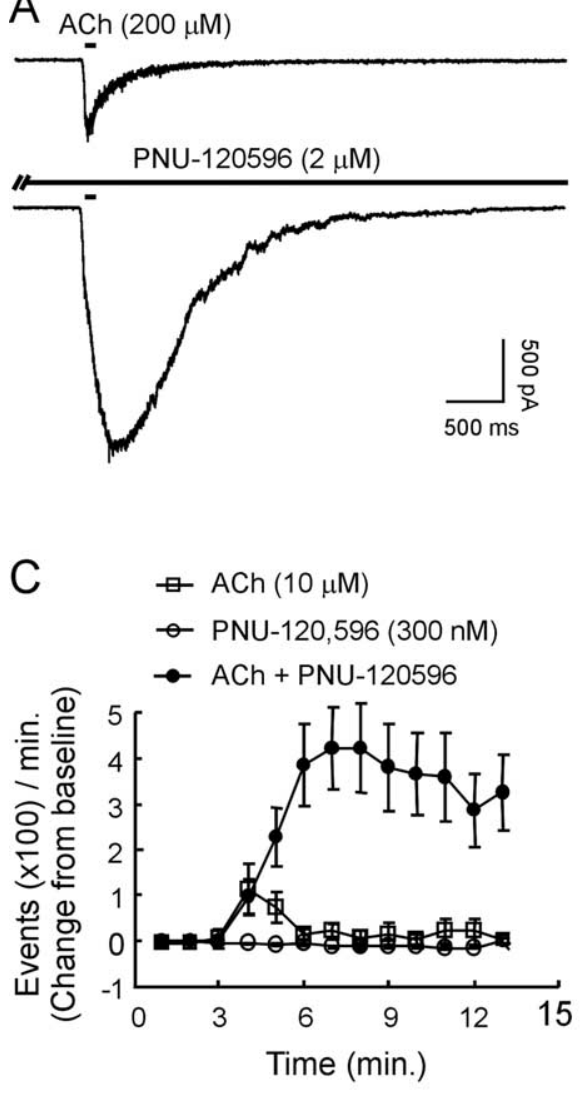

B

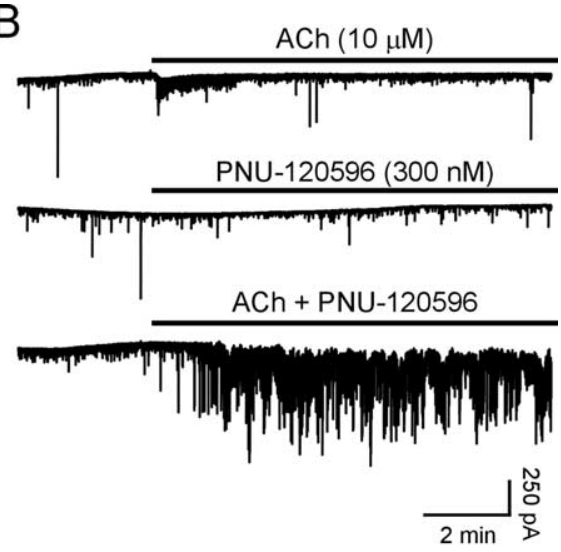

D

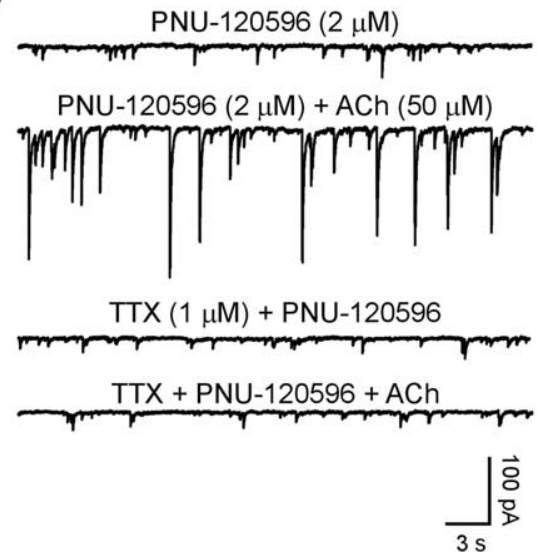

Figure 7. PNU-120596 enhances the excitatory actions of ACh on hippocampal interneurons in isolated slices. A, Effect of PNU-120596 on the ACh-evoked current in a stratum radiatum hippocampal interneuron. The voltage-clamp records show the inward current evoked by ACh $(0.2 \mathrm{~mm})$ in control conditions (top trace) and after the addition of PNU-120596 (2 $\mu \mathrm{m})$ to the perfusion solution (bottom trace). The horizontal bar above the current traces indicates the time during which $\mathrm{ACh}$ was pressure ejected. The patch pipette was filled with a K-gluconate-containing solution, and the holding potential was $-70 \mathrm{mV}$. B, Continuous recording from pyramidal neurons showing spontaneously occurring GABAergic synaptic activity. After $3 \mathrm{~min}$ of baseline measurement, ACh (10 $\mu \mathrm{M})$, PNU-120596 $(0.3 \mu \mathrm{M})$, or the combination of ACh $(10 \mu \mathrm{M})$ and PNU-120596 (0.3 $\mu \mathrm{M})$ was bath applied for an additional $10 \mathrm{~min}$. C, Plot of the change in synaptic activity relative to the baseline period measured for the three experimental groups. Data points are the average number of events recorded during consecutive $60 \mathrm{~s}$ bins for ACh alone (open squares; $n=5$ ), PNU-120596 alone (open circles; $n=5$ ), and ACh plus PNU-120596 (filled circles; $n=6$ ). In each case, baseline activity was measured over a $3 \mathrm{~min}$ period, and test solutions were bath applied for $10 \mathrm{~min}$. $\boldsymbol{D}$, Effect of ACh on spontaneous GABAergic IPSCs in a CA1 pyramidal neuron. All recordings were performed in the presence of PNU-120596 (2 $\mu \mathrm{m})$. The synaptic activity was recorded in the absence (first and third traces) and in the presence (second and fourth traces) of ACh (50 $\mu \mathrm{M})$. TTX (1 $\mu \mathrm{M}$ ) was present when the third and fourth traces were recorded. Patch pipettes were filled with a CsCl-containing solution, and the holding potential was $-70 \mathrm{mV}$. Note that TTX suppressed the ACh-dependent increase in inhibitory synaptic activity. Error bars represent SEM.

baseline revealed discrete unitary events of $\sim 4.5 \mathrm{pA}$ and of a long open time. Openings of such long duration were never observed in the absence of PNU-120596. Unitary current amplitudes estimated by nonstationary noise analysis were $-2.7 \pm 0.8 \mathrm{pA}(n=$ $5)$ and $-4.4 \pm 0.5 \mathrm{pA}(n=4)$ in the absence and presence of PNU-120596, respectively. The estimated unitary amplitude of $-4.4 \mathrm{pA}$ in the presence of PNU-120596 is consistent with the measured amplitude of the resolved events. It is difficult to draw a conclusion regarding the effect of PNU-120596 on the unitary conductance. The amplitude of the very brief events measured in the absence of PNU-120596 is likely underestimated because of the cutoff frequency of the recording conditions. Thus, the unitary currents were either slightly increased by PNU-120596 or not affected. Together, these data suggest that the major effect of PNU-120596 was to increase the mean open time while having little if any effect on either the ion selectivity or the unitary conductance.

PNU-120596 enhances $\alpha 7$ nAChR function in rat hippocampal interneurons and modulates GABAergic synaptic transmission in isolated brain slices

Rat hippocampal interneurons are known to express $\alpha 7 \mathrm{nAChR}$ subunit protein, and it has been proposed that these cells express functional nAChRs that resemble homomeric $\alpha 7$ receptors expressed in cell lines (Alkondon et al., 1997; Jones and Yakel, 1997; Frazier et al., 1998; Ji and Dani, 2000). To assess the effects of PNU120596 on native receptors, we recorded ACh-evoked currents in CA1 stratum radiatum interneurons. As expected, pressure application of ACh ( $0.2 \mathrm{~mm})$ evoked fast inward currents, which showed rapid desensitization in six of seven interneurons voltage clamped at $-70 \mathrm{mV}$, with an average peak amplitude of $209 \pm 86 \mathrm{pA}$ (range, 39-676 pA) (Fig. 7A, top trace). Adding PNU-120596 (2 $\mu \mathrm{M}$ for $12-20$ $\mathrm{min}$ ) in the perfusing solution enhanced the ACh-evoked currents in all interneurons investigated. Moreover, in one cell, an ACh-evoked response was observed in the presence of PNU-120596, whereas no detectable current could be observed in control conditions. The average AChevoked response was increased by more than four times to $867 \pm 259 \mathrm{pA} ; p<0.05$ (range, 132-2098 pA) (Fig. 7A, bottom trace). Concomitantly, PNU-120596 caused a significant increase in the response duration. In control conditions, ACh currents returned to baseline levels within $1.35 \pm 0.08 \mathrm{~s}$, whereas in the presence of PNU-120596, complete decay was observed only after $3.5 \pm 0.4 \mathrm{~s}(p<0.01)$. Both responses recorded in control and during superfusion with PNU-120596 were suppressed by the $\alpha 7$-selective antagonist MLA at $10 \mathrm{nM}(n=3)$, confirming that, as in oocytes and cultured neurons, PNU-120596 potentiated the ACh responses mediated by $\alpha 7$ containing nAChRs.

The ability of PNU-120596 to influence synaptic transmission was evaluated by recording spontaneously occurring GABAergic synaptic events from CA1 pyramidal neurons in response to challenges with ACh $(10 \mu \mathrm{M})$, PNU-120596 (300 nM), or the combination of ACh and PNU-120596 (Fig. 7 B, C). GABAergic synaptic events were recorded in the presence of glutamate receptor antagonists and with high intracellular chloride (see Materials and Methods). Under these conditions, the recorded synaptic events should be exclusively GABAergic, and it was shown previously that they can be blocked by bicuculline (Zaninetti and Raggenbass, 2000; Ogier and Raggenbass, 2003). When applied alone, PNU-120596 produced no detectable change in the frequency of spontaneously occurring synaptic events (baseline ac- 
tivity of $19.7 \pm 2.7$ vs $16.2 \pm 7.8$ events $/ \mathrm{min}$ in the presence of PNU-120596; $n=5)$. In the same configuration, continuous bath application of ACh produced a transient increase in synaptic activity that declined toward baseline levels after $\sim 3$ min (baseline activity of $38.9 \pm 11.6$ events/min vs peak activity of $151.4 \pm 67.3$ events/min in the presence of ACh; $n=5)$. PNU-120596 markedly enhanced the actions of ACh on synaptic transmission, resulting in a large and long-lasting increase in GABAergic synaptic activity (baseline activity of $22.3 \pm 4.2$ events/min vs peak activity of $442.8 \pm 97.2$ events/min in the presence of ACh plus PNU120596; $n=6$ ).

Neuronal nAChRs can be located on cell somata or dendrites, where they can mediate direct postsynaptic effects, or on axon terminals, where they can modulate neurotransmitter release (for review, see Alkondon and Albuquerque, 2004). Thus, the positive modulation by PNU-120596 of the ACh-stimulated synaptic transmission in hippocampal slices could be attributable to PNU120596 acting on nAChRs located on the somatodendritic membrane or on axon terminals of GABAergic interneurons. To distinguish between these possibilities, we compared the effects of PNU-120596 and ACh on both spontaneous and miniature GABAergic IPSCs (mIPSCs) in CA1 pyramidal neurons. All recordings were performed while PNU-120596 (2 $\mu \mathrm{M})$ was present in the bath solution. In an initial series of experiments, ACh (50 $\mu \mathrm{M})$ was bath applied in the absence and presence of TTX $(1 \mu \mathrm{M})$. In the absence of TTX, ACh increased the frequency of events and thus decreased the mean IPSC interevent interval from $83 \pm 47$ to $47 \pm 12 \mathrm{~ms}$ (Fig. $7 D$, first and second traces). In addition, ACh increased the mean IPSC amplitude from $32 \pm 1$ to $77 \pm 9 \mathrm{pA}$ ( $n=3 ; p<0.01$ in all cases). In contrast, when applied in the presence of TTX, ACh did not significantly affect either the interevent interval $(130 \pm 58 \mathrm{~ms})$ or the amplitude $(35 \pm 3 \mathrm{pA})$ of action potential-independent mIPSCs recorded from the same three pyramidal neurons (Fig. $7 D$, third and fourth traces). In a second series of experiments, pyramidal neurons were recorded while ACh $(200 \mu \mathrm{M})$ was pressure ejected on a nearby stratum radiatum interneuron; as above, PNU-120596 was present at 2 $\mu \mathrm{M}$ throughout. ACh caused an increase in the frequency of IPSCs in all of the pyramidal neurons tested in this configuration ( $n=9 ; p<0.01$ in all cases). In control conditions, the mean IPSC interevent interval was $197 \pm 54 \mathrm{~ms}$, whereas after ACh ejection, the interevent interval decreased to $52 \pm 11 \mathrm{~ms}$. The amplitude of the IPSCs was increased in three of these neurons by $185-770 \%(p<0.01$ in all cases $)$ and was decreased in one neuron by $47 \%(p<0.01)$. It remained unchanged in the five remaining neurons. mIPSCs were recorded in the presence of TTX $(1 \mu \mathrm{M})$ in five of nine pyramidal neurons. In these five neurons, the mean mIPSC interevent interval was $164 \pm 36 \mathrm{~ms}$, and the mean mIPSC amplitude was $22 \pm 4 \mathrm{pA}$. Pressure ejection of ACh did not significantly affect the interevent interval or the amplitude of mIPSCs in any of these neurons. Together, these data suggest that PNU-120596 positively modulated the AChdependent increase in hippocampal inhibitory transmission by reinforcing the direct excitatory effect of ACh on GABAergic interneurons.

\section{Effects of PNU-120596 on hippocampal auditory gating in anesthetized rats}

Recordings of hippocampal field potentials revealed responses evoked by auditory stimuli in anesthetized rats (Fig. $8 \mathrm{~A}$ ). As has been reported previously, the second of two evoked responses spaced $500 \mathrm{~ms}$ apart is reduced relative to the first, a process known as auditory gating (Bickford-Wimer et al., 1990). Audi-
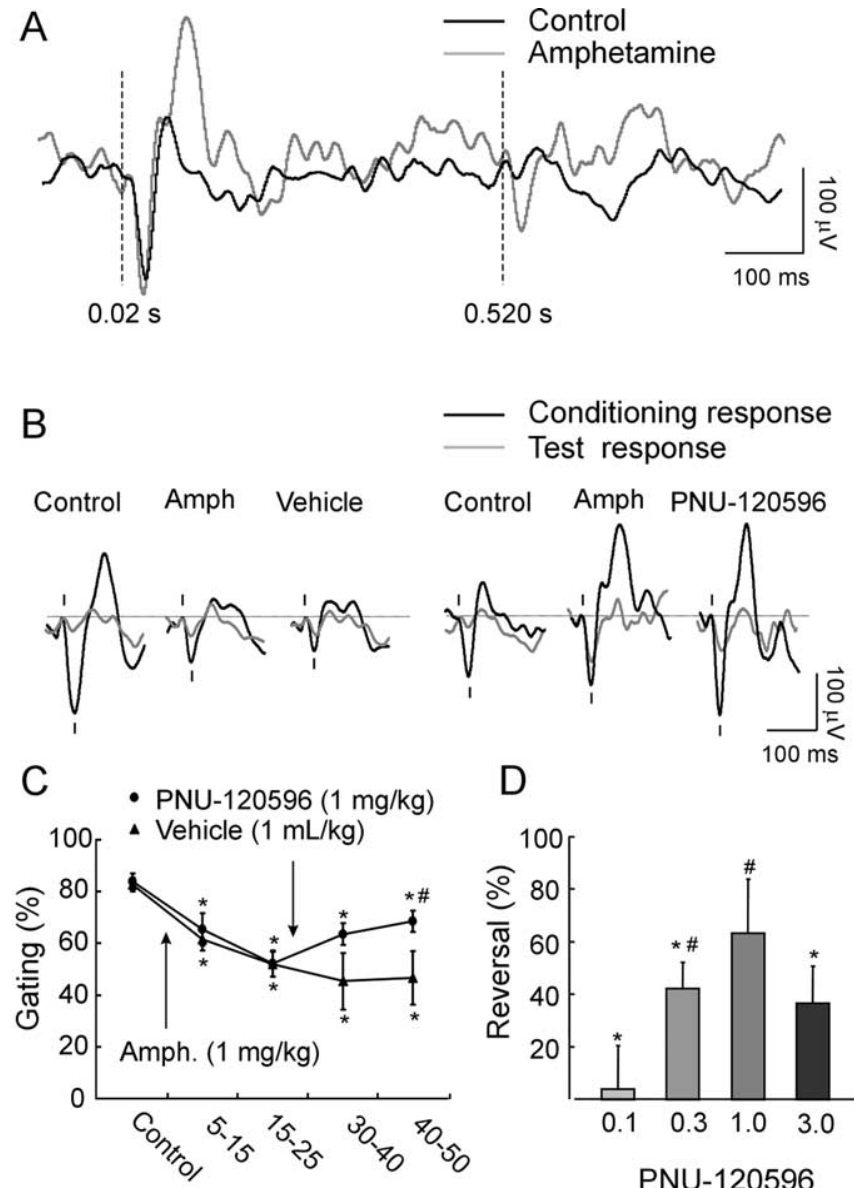

D

Time post Amph. (min.)

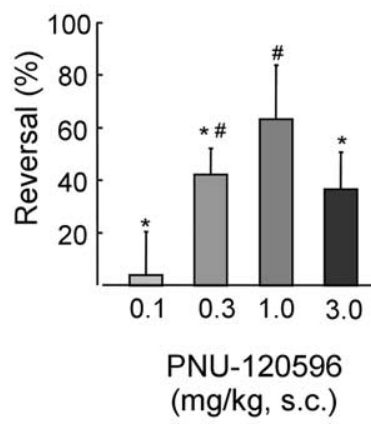

Figure 8. PNU-120596 improves auditory gating deficits induced by D-amphetamine in anesthetized rats. $\boldsymbol{A}$, Hippocampal auditory evoked potentials (summation of 50 consecutive evoked potentials, displayed at a continuous $1 \mathrm{~s}$ sweep) in response to conditioning and test auditory tones (indicated by dashed lines; intertone interval, $0.5 \mathrm{~s}$ ) in control conditions (black trace) and after administration of o-amphetamine (gray trace; $1.0 \mathrm{mg} / \mathrm{kg}$, i.v.). B, Typical hippocampal auditory evoked potentials (summation of 50 consecutive evoked potentials) in response to conditioning (black trace) and test (gray trace) auditory tones in control conditions after administration of D-amphetamine (Amph; $1.0 \mathrm{mg} / \mathrm{kg}$, i.v.) and after a subsequent administration of vehicle (PBS) or PNU-120596 (1 mg/kg, i.v.). C, Average of hippocampal auditory gating in rats (expressed as a percentage) during the control period, after D-amphetamine (1.0 $\mathrm{mg} / \mathrm{kg}$, i.v.), and after subsequent administration of vehicle (PBS; $1 \mathrm{ml} / \mathrm{kg}$, i.v.; $n=8$ ) or PNU-120596 (1 mg/kg, i.v.; $n=7$ ). Each point represents mean \pm SEM percentage gating; auditory gating was calculated from 50 consecutive evoked potentials ( ${ }^{*} p<0.01$ vs AMP; ${ }^{*} p<0.01$ vs control). D, Dose-response effect of PNU-120596 administered subcutaneously on an amphetamine-induced gating deficit expressed as percentage of reversal ( ${ }^{\#} p<0.05$ vs AMP; * $p<0.05$ vs vehicle; total of 46 animals included in dose-response). Error bars represent $S E M$.

tory gating can be impaired by administration of $\mathrm{D}$-amphetamine $(1 \mathrm{mg} / \mathrm{kg}$, i.v. $)$ in the majority of treated rats, as indicated by a significant decrease in the ratio of the test response to the conditioning response (Fig. $8 A, B$ ). As shown in Figure $8 C$, intravenous administration of PNU-120596 ( $1 \mathrm{mg} / \mathrm{kg} ; n=7)$ significantly reversed the amphetamine-induced gating deficit, whereas administration of the vehicle $(1 \mathrm{ml} / \mathrm{kg}$, i.v.; $n=8)$ produced no improvement in gating over the same period of time. PNU120596 also reversed the amphetamine-induced gating deficits with intravenous administration of $0.3 \mathrm{mg} / \mathrm{kg}$ ( $47 \pm 3.8 \%$ reversal; $n=6 ; p<0.01)$ and $0.1 \mathrm{mg} / \mathrm{kg}(37 \pm 4.2 \%$ reversal; $n=6$; $p<0.05)$. The concentrations of PNU-120596 measured in the brains of rats receiving intravenous doses of $0.1,0.3$, and $1 \mathrm{mg} / \mathrm{kg}$ were $81 \pm 31,348 \pm 189$, and $1554 \pm 584 \mathrm{nM}$, respectively. 
Consistent with the results obtained with intravenous doses, Figure $8 D$ shows the dose-response relationship achieved with subcutaneous administration of PNU-120596. The minimal effective dose under these conditions was $0.3 \mathrm{mg} / \mathrm{kg}$ and was associated with a brain exposure of $76 \pm 17 \mathrm{nM}$ (Fig. $8 D$ ).

\section{Discussion}

Like all ligand-gated ion channels, the $\alpha 7 \mathrm{nAChR}$ is both activated and desensitized by agonists in a concentration-dependent manner, and it can become desensitized at lower agonist concentrations than those required to substantially activate the receptor (for review, see Quick and Lester, 2002). Thus, under conditions of continuous exposure, such as those that may be approached with chronic drug treatment, $\alpha 7 \mathrm{nAChR}$ agonists may have a relatively narrow effective-concentration range limited to the region of overlap in which the receptors are activated but not fully desensitized (for review, see Hogg and Bertrand, 2004). Consistent with this idea, it has been suggested that receptor desensitization may contribute to the relatively modest effects of nicotine on specific neurocognitive measures in human clinical studies (Smith et al., 2002; Harris et al., 2004).

Unlike agonists, PAMs do not directly activate or desensitize ligand-gated receptors; instead, they enhance the sensitivity and/or efficacy of the receptor during agonist activation. Several compounds have been identified previously that are PAMs of the $\alpha 7$ nAChR, including ivermectin (Krause et al., 1998), 5-hydroxyindole (Zwart et al., 2002), and peptides including serum albumins (Conroy et al., 2003), SLURP (secreted mammalian Ly-6/uPAR-related protein) (Chimienti et al., 2003), and a peptide fragment of acetylcholinesterase (Zbarsky et al., 2004). All of these compounds potentiate the peak agonist-evoked response mediated by the $\alpha 7 \mathrm{nAChR}$, but none of these agents substantially modifies the duration of the response. Thus, PNU120596 represents a new class of allosteric modulator of the $\alpha 7$ nAChR. Similar to the actions of some allosteric modulators of AMPA receptors (for review, see O'Neill et al., 2004), PNU120596 increased the peak agonist-evoked response and markedly prolonged the macrosopic currents in the presence of agonist, possibly by interfering with the desensitization process. Thus, the net effect of PNU-120596 was to substantially increase total ion flux at all effective agonist concentrations. PNU-120596 also significantly increased the slope of the ACh concentrationresponse relationship (Hill coefficient increased from 2.2 to 4 ) and increased the potency of ACh by $\sim 10$-fold. The present work provides good evidence that a major effect of PNU-120596 was to increase the mean open time while having relatively little or no effect on either the unitary conductance or ion selectivity of the channel. These results suggest that PNU-120596 does not produce major structural changes in the ion-conduction pathway such as those that might be obtained with the formation of a new conducting state. One possible explanation is that PNU-120596 stabilizes the existing open state of the channel, a mechanism distinct from that produced by the L247T mutation that converts the desensitized state of the receptor into a conducting state (Bertrand et al., 1992).

It has been well established that, within the rat hippocampus, $\alpha 7 \mathrm{nAChRs}$ are located on inhibitory interneurons and that activation of those receptors can increase hippocampal GABAergic neurotransmission (Alkondon et al., 1997; Radcliffe et al., 1999; Kofalvi et al., 2000; Buhler and Dunwiddie, 2002). In the present study, PNU-120596 was found to increase and prolong the $\alpha 7$ nAChR-mediated currents recorded from hippocampal interneurons and substantially enhance the ACh-evoked GABAergic synaptic transmission measured in pyramidal cells. To determine whether PNU-120596 could also enhance $\alpha 7 \mathrm{nAChR}$ function in response to endogenously released $\mathrm{ACh}$, in vivo electrophysiology recordings were used to evaluate its effects on auditory gating in rats. Auditory gating is measured as the suppression of the second of paired auditory evoked potentials when the stimuli are given at sufficiently short intervals, a process proposed to result from local release of GABA after the initial auditory stimulation (for review, see Martin et al., 1994). Previous work has shown that agonists of the $\alpha 7 \mathrm{nAChR}$ can improve gating deficits in rats regardless of whether they are induced pharmacologically (Stevens et al., 1999; Hajós et al., 2005), genetically (Stevens and Wear, 1997), or behaviorally (O’Neill et al., 2003). However, unlike agonists, PNU-120596 has no detectable activity when added alone and can only enhance receptor function in the presence of an agonist. Two conclusions can be drawn from the present results showing that PNU-120596 reversed the amphetamineinduced auditory gating deficit. First, sufficient levels of an endogenous agonist (ACh or choline) must have been present at the relevant receptors at the time of the measurements. Second, the positive outcome indicates that a sufficient concentration of PNU-120596 entered the brain and reached the target receptor when administered systemically (intravenously or subcutaneously). Brain concentrations of PNU-120596 associated with minimally effective doses were $\sim 81$ and $76 \mathrm{nM}$ for intravenous and subcutaneous administration, respectively. This exposure is comparable with the concentration that produced a measurable modulation of ACh-evoked currents in hippocampal neurons $(100 \mathrm{~nm})$ (Fig. $3 A b)$ and overlaps with the lower range of the concentration-response determined from $\alpha 7^{\star}$-expressing $\mathrm{SH}$ EP1 cells (Fig. 1C).

In summary, the data presented in this study demonstrate that PNU-120596 represents a novel PAM of the $\alpha 7 \mathrm{nAChR}$ that can increase the maximal agonist-evoked current and markedly slow the decay of the currents in the continued presence of agonist. PNU-120596 produces these effects in part by increasing the channel mean open time, but it has no effect on the ion selectivity and relatively little, if any, effect on the unitary conductance. Importantly, this work demonstrates that PAMs such as PNU120596 can positively influence the function of brain circuitry in vivo and thus represents a potential new therapy for a variety of psychiatric and neurological disorders that are associated with $\alpha 7$ nAChR dysfunction.

\section{References}

Albuquerque EX, Santos MD, Alkondon M, Pereira EF, Maelicke A (2001) Modulation of nicotinic receptor activity in the central nervous system: a novel approach to the treatment of Alzheimer disease. Alzheimer Dis Assoc Disord 15 [Suppl 1]:S19-S25.

Alkondon M, Albuquerque EX (1993) Diversity of nicotinic acetylcholine receptors in rat hippocampal neurons. I. Pharmacological and functional evidence for distinct structural subtypes. J Pharmacol Exp Ther 265:1455-1473.

Alkondon M, Albuquerque EX (2004) The nicotinic acetylcholine receptor subtypes and their function in the hippocampus and cerebral cortex. Prog Brain Res 145:109-120.

Alkondon M, Pereira EFR, Barbosa CTF, Albuquerque EX (1997) Neuronal nicotinic acetylcholine receptor activation modulates gammaaminobutyric acid release from CA1 neurons of rat hippocampal slices. J Pharmacol Exp Ther 283:1396-1411.

Alkondon M, Pereira EF, Eisenberg HM, Albuquerque EX (1999) Choline and selective antagonists identify two subtypes of nicotinic acetylcholine receptors that modulate GABA release from CA1 interneurons in rat hippocampal slices. J Neurosci 19:2693-2705.

Arendash GW, Sengstock GJ, Sanberg PR, Kem WR (1995) Improved learn- 
ing and memory in aged rats with chronic administration of the nicotinic receptor agonist GTS-21. Brain Res 674:252-259.

Bertrand D, Cooper E, Valera S, Rungger D, Ballivet M (1991) Electrophysiology of neuronal nicotinic acetylcholine receptors expressed in Xenopus oocytes following nuclear injection of genes or cDNA. In: Methods in neuroscience, Vol 4 (Conn M, ed), pp 174-193. New York: Academic.

Bertrand D, Devillers-Thiery A, Revah F, Galzi JL, Hussy N, Mulle C, Bertrand S, Ballivet M, Changeux JP (1992) Unconventional pharmacology of a neuronal nicotinic receptor mutated in the channel domain. Proc Natl Acad Sci USA 89:1261-1265.

Bettany JH, Levin ED (2001) Ventral hippocampal alpha 7 nicotinic receptor blockade and chronic nicotine effects on memory performance in the radial-arm maze. Pharmacol Biochem Behav 70:467-474.

Bickford-Wimer PC, Nagamoto H, Johnson R, Adler LE, Egan M, Rose GM, Freedman R (1990) Auditory sensory gating in hippocampal neurons: a model system in the rat. Biol Psychiatry 27:183-192.

Brewer GJ (1997) Isolation and culture of adult rat hippocampal neurons. J Neurosci Methods 71:143-155.

Briggs CA, Anderson DJ, Brioni JD, Buccafusco JJ, Buckley MJ, Campbell JE, Decker MW, Donnelly-Roberts D, Elliott RL, Gopalakrishnan M, Holladay MW, Hui YH, Jackson WJ, Kim DJ, Marsh KC, O’Neill A, Prendergast MA, Ryther KB, Sullivan JP, Arneric SP (1997) Functional characterization of the novel neuronal nicotinic acetylcholine receptor ligand GTS-21 in vitro and in vivo. Pharmacol Biochem Behav 57:231-241.

Buhler AV, Dunwiddie TV (2002) Alpha7 nicotinic acetylcholine receptors on GABAergic interneurons evoke dendritic and somatic inhibition of hippocampal neurons. J Neurophysiol 87:548-557.

Chimienti F, Hogg RC, Plantard L, Lehmann C, Brakch N, Fischer J, Huber M, Bertrand D, Hohl D (2003) Identification of SLURP-1 as an epidermal neuromodulator explains the clinical phenotype of Mal de Meleda. Hum Mol Genet 12:3017-3024.

Conroy WG, Liu QS, Nai Q, Margiotta JF, Berg DK (2003) Potentiation of alpha7-containing nicotinic acetylcholine receptors by select albumins. Mol Pharmacol 63:419-428.

Court J, Spurden D, Lloyd S, McKeith I, Ballard C, Cairns N, Kerwin R, Perry R, Perry E (1999) Neuronal nicotinic receptors in dementia with Lewy bodies and schizophrenia: alpha-bungarotoxin and nicotine binding in the thalamus. J Neurochem 73:1590-1597.

Couturier S, Bertrand D, Matter JM, Hernandez MC, Bertrand S, Millar N, Valera S, Barkas T, Ballivet M (1990) A neuronal nicotinic acetylcholine receptor subunit (alpha 7) is developmentally regulated and forms a homo-oligomeric channel blocked by alpha-BTX. Neuron 5:847-856.

De Luca V, Wong AH, Muller DJ, Wong GW, Tyndale RF, Kennedy JL (2004) Evidence of association between smoking and alpha7 nicotinic receptor subunit gene in schizophrenia patients. Neuropsychopharmacology 29:1522-1526.

Felix R, Levin ED (1997) Nicotinic antagonist administration into the ventral hippocampus and spatial working memory in rats. Neuroscience 81:1009-1017.

Frazier CJ, Rollins YD, Breese CR, Leonard S, Freedman R, Dunwiddie TV (1998) Acetylcholine activates an $\alpha$-bungarotoxin-sensitive nicotinic current in rat hippocampal interneurons, but not pyramidal cells. J Neurosci 18:1187-1195.

Freedman R, Hall M, Adler LE, Leonard S (1995) Evidence in postmortem brain tissue for decreased numbers of hippocampal nicotinic receptors in schizophrenia. Biol Psychiatry 38:22-33.

Freedman R, Coon H, Myles-Worsley M, Orr-Urtreger A, Olincy A, Davis A, Polymeropoulos M, Holik J, Hopkins J, Hoff M, Rosenthal J, Waldo MC, Reimherr F, Wender P, Yaw J, Young DA, Breese CR, Adams C, Patterson D, Adler LE, et al. (1997) Linkage of a neurophysiological deficit in schizophrenia to a chromosome 15 locus. Proc Natl Acad Sci USA 94:587-592.

Gray R, Rajan AS, Radcliffe KA, Yakehiro M, Dani JA (1996) Hippocampal synaptic transmission enhanced by low concentrations of nicotine. Nature 383:713-716.

Guan ZZ, Zhang X, Blennow K, Nordberg A (1999) Decreased protein level of nicotinic receptor alpha7 subunit in the frontal cortex from schizophrenic brain. NeuroReport 10:1779-1782.

Hajós M, Hurst RS, Hoffmann WE, Krause M, Wall TM, Higdon NR, Groppi VE (2005) The selective alpha7 nicotinic acetylcholine receptor agonist PNU-282987 enhances GABAergic synaptic activity in brain slices and restores auditory gating deficits in anesthetized rats. J Pharmacol Exp Ther 312:1213-1222.

Harris JG, Kongs S, Allensworth D, Martin L, Tregellas J, Sullivan B, Zerbe G, Freedman R (2004) Effects of nicotine on cognitive deficits in schizophrenia. Neuropsychopharmacology 29:1378-1385.

Hogg RC, Bertrand D (2004) Nicotinic acetylcholine receptors as drug targets. Curr Drug Targets CNS Neurol Disord 3:123-130.

Ji D, Dani JA (2000) Inhibition and disinhibition of pyramidal neurons by activation of nicotinic receptors on hippocampal interneurons. J Neurophysiol 83:2682-2690.

Jones S, Yakel JL (1997) Functional nicotinic ACh receptors on interneurones in the rat hippocampus. J Physiol (Lond) 504:603-610.

Kitagawa H, Takenouchi T, Azuma R, Wesnes KA, Kramer WG, Clody DE, Burnett AL (2003) Safety, pharmacokinetics, and effects on cognitive function of multiple doses of GTS-21 in healthy, male volunteers. Neuropsychopharmacology 28:542-551.

Kofalvi A, Sperlagh B, Zelles T, Vizi ES (2000) Long-lasting facilitation of 4-amino-n- $\left[2,3-{ }^{3} \mathrm{H}\right]$ butyric acid $\left(\left[{ }^{3} \mathrm{H}\right] \mathrm{GABA}\right)$ release from rat hippocampal slices by nicotinic receptor activation. J Pharmacol Exp Ther 295:453-462.

Krause M, Hoffmann WE, Hajós M (2003) Auditory sensory gating in hippocampus and reticular thalamic neurons in anesthetized rats. Biol Psychiatry 53:244-253.

Krause RM, Buisson B, Bertrand S, Corringer PJ, Galzi JL, Changeux JP, Bertrand D (1998) Ivermectin: a positive allosteric effector of the alpha7 neuronal nicotinic acetylcholine receptor. Mol Pharmacol 53:283-294.

Levin ED (2002) Nicotinic receptor subtypes and cognitive function. J Neurobiol 53:633-640.

Levin ED, Bettegowda C, Blosser J, Gordon J (1999) AR-R17779, and alpha7 nicotinic agonist, improves learning and memory in rats. Behav Pharmacol 10:675-680.

Li X, Rainnie DG, McCarley RW, Greene RW (1998) Presynaptic nicotinic receptors facilitate monoaminergic transmission. J Neurosci 18:1904-1912.

Maelicke A (2000) Allosteric modulation of nicotinic receptors as a treatment strategy for Alzheimer's disease. Dement Geriatr Cogn Disord 11 [Suppl 1]:11-18.

Maggi L, Sher E, Cherubini E (2001) Regulation of GABA release by nicotinic acetylcholine receptors in the neonatal rat hippocampus. J Physiol (Lond) 536:89-100.

Martin LF, Kem WR, Freedman R (2004) Alpha-7 nicotinic receptor agonists: potential new candidates for the treatment of schizophrenia. Psychopharmacology 174:54-64.

Marutle A, Zhang X, Court J, Piggott M, Johnson M, Perry R, Perry E, Nordberg A (2001) Laminar distribution of nicotinic receptor subtypes in cortical regions in schizophrenia. J Chem Neuroanat 22:115-126.

McGehee DS, Heath MJ, Gelber S, Devay P, Role LW (1995) Nicotine enhancement of fast excitatory synaptic transmission in CNS by presynaptic receptors. Science 269:1692-1696.

Meyer EM, Tay ET, Zoltewicz JA, Meyers C, King MA, Papke RL, De Fiebre CM (1998) Neuroprotective and memory-related actions of novel alpha-7 nicotinic agents with different mixed agonist/antagonist properties. J Pharmacol Exp Ther 284:1026-1032.

Ogier R, Raggenbass M (2003) Action of tachykinins in the rat hippocampus: modulation of inhibitory synaptic transmission. Eur J Neurosci $17: 2639-2647$.

O’Neill HC, Rieger K, Kem WR, Stevens KE (2003) DMXB, an alpha7 nicotinic agonist, normalizes auditory gating in isolation-reared rats. Psychopharmacology 169:332-339.

O’Neill MJ, Bleakman D, Zimmerman DM, Nisenbaum ES (2004) AMPA receptor potentiators for the treatment of CNS disorders. Curr Drug Targets CNS Neurol Disord 3:181-194.

Paxinos G, Watson C (1986) The rat brain in stereotaxic coordinates. Sydney: Academic.

Quick MW, Lester RA (2002) Desensitization of neuronal nicotinic receptors. J Neurobiol 53:457-478.

Radcliffe KA, Fisher JL, Gray R, Dani JA (1999) Nicotinic modulation of glutamate and GABA synaptic transmission of hippocampal neurons. Ann NY Acad Sci 868:591-610.

Schilstrom B, Svensson HM, Svensson TH, Nomikos GG (1998) Nicotine and food induced dopamine release in the nucleus accumbens of the rat: putative role of alpha7 nicotinic receptors in the ventral tegmental area. Neuroscience 85:1005-1009. 
Séguéla P, Wadiche J, Dineley-Miller K, Dani JA, Patrick JW (1993) Molecular cloning, functional properties, and distribution of rat brain $\alpha 7$ : a nicotinic cation channel highly permeable to calcium. J Neurosci 13:596-604.

Smith RC, Singh A, Infante M, Khandat A, Kloos A (2002) Effects of cigarette smoking and nicotine nasal spray on psychiatric symptoms and cognition in schizophrenia. Neuropsychopharmacology 27:479-497.

Stevens KE, Wear KD (1997) Normalizing effects of nicotine and a novel nicotinic agonist on hippocampal auditory gating in two animal models. Pharmacol Biochem Behav 57:869-874.

Stevens KE, Kem WR, Mahnir VM, Freedman R (1998) Selective alpha7nicotinic agonists normalize inhibition of auditory response in DBA mice. Psychopharmacology 136:320-327.

Stevens KE, Kem WR, Freedman R (1999) Selective alpha 7 nicotinic receptor stimulation normalizes chronic cocaine-induced loss of hippocampal sensory inhibition in C3H mice. Biol Psychiatry 46:1443-1450.

Summers KL, Kem WR, Giacobini E (1997) Nicotinic agonist modulation of neurotransmitter levels in the rat frontoparietal cortex. Jpn J Pharmacol 74:139-146.

Van Kampen M, Selbach K, Schneider R, Schiegel E, Boess F, Schreiber R (2004) AR-R 17779 improves social recognition in rats by activation of nicotinic alpha7 receptors. Psychopharmacology 172:375-383.

White HK, Levin ED (2004) Chronic transdermal nicotine patch treatment effects on cognitive performance in age-associated memory impairment. Psychopharmacology 171:465-471.

Woodruff-Pak DS (2003) Mecamylamine reversal by nicotine and by a partial alpha7 nicotinic acetylcholine receptor agonist (GTS-21) in rabbits tested with delay eyeblink classical conditioning. Behav Brain Res 143:159-167.

Woodruff-Pak DS, Li YT, Kem WR (1994) A nicotinic agonist (GTS-21), eyeblink classical conditioning, and nicotinic receptor binding in rabbit brain. Brain Res 645:309-317.

Zaninetti M, Raggenbass M (2000) Oxytocin receptor agonists enhance inhibitory synaptic transmission in the rat hippocampus by activating interneurons in stratum pyramidale. Eur J Neurosci 12:3975-3984.

Zarei MM, Radcliffe KA, Chen D, Patrick JW, Dani JA (1999) Distributions of nicotinic acetylcholine receptor alpha7 and beta2 subunits on cultured hippocampal neurons. Neuroscience 88:755-764.

Zbarsky V, Thomas J, Greenfield S (2004) Bioactivity of a peptide derived from acetylcholinesterase: involvement of an ivermectin-sensitive site on the alpha 7 nicotinic receptor. Neurobiol Dis 16:283-289.

Zwart R, De Filippi G, Broad LM, McPhie GI, Pearson KH, Baldwinson T, Sher E (2002) 5-Hydroxyindole potentiates human alpha 7 nicotinic receptor-mediated responses and enhances acetylcholine-induced glutamate release in cerebellar slices. Neuropharmacology 43:374-384. 